\title{
TRANSVERSALIZANDO SABERES NAS ARTES VISUAIS EM PROJETO DE EXTENSÃO - O CINE PIBID NA ESCOLA
}

\section{TRANSVERSALIZING KNOWLEDGE IN VISUAL ARTS IN AN EXTENSION PROJECT - CINE PIBID IN SCHOOL}

\section{RESUMO:}

Através desse artigo, relatam-se processos de extensão, ensino e pesquisa que refletem sobre as ações e práticas desenvolvidas com o cinema no Subprojeto Artes Visuais do Pibid/UFPel (Projeto Institucional de Bolsas de Iniciação à Docência), visando a formação de futuros professores de Artes Visuais. Objetiva-se socializar as experiências vividas pelos bolsistas no projeto de extensão intitulado CINE PIBID Transversalizando Saberes nas Artes Visuais, desenvolvido em duas escolas públicas de Ensino Fundamental e Médio atendidas pelo programa, a partir do segundo semestre de 2015 e no decorrer de 2016. O CINE PIBID aproximou a universidade da realidade dos alunos, reforçando o trânsito com os diversos repertórios na escola - o conhecimento formal e o informal, por meio de ações marcadas pelo conhecimento da área de estudo, afetividade, respeito mútuo e tolerância à diversidade.

Palavras-chave: Artes Visuais; Cinema; Interdisciplinaridade; PIBID.

\begin{abstract}
:
This article reports the extension, teaching and research processes that reflect on the actions and practices developed with cinema in the Subproject Visual Arts of PIBID/UFPel (Institutional Project of Scholarship for Begginners Teachears) aimed to train future Visual Arts teachers. It aims to socialize the experiences of the scholarship holders of the extension project CINE PIBID - Transversalizing Knowledge in Visual Arts, developed in two public schools of primary and secondary education in the second semester of 2015 and in 2016. CINE PIBID brought university closer to the reality of students, reinforcing various repertoires in school - the formal and informal knowledge, through actions based on the knowledge of the area of study, affection, mutual respect and tolerance to the diversity.
\end{abstract}

Keywords: Visual Arts; Cinema; Interdisciplinarity; PIBID.

${ }^{*}$ Professora da Universidade Federal de Pelotas (UFPel), Pelotas - RS, Brasil. E-mail: maristaniz@hotmail.com 


\section{CINE PIBID, um projeto para os saberes nas Artes} Visuais

A partir das discussões realizadas durante as reuniões do grupo PIBID - Artes Visuais, em que se debatia a necessidade da inserção do cinema nas escolas, visto seu potencial educativo (DUARTE, 2002), elaborou-se o projeto CINE PIBID Transversalizando saberes nas Artes Visuais ${ }^{1}$, que teve como objetivo propiciar a discussão e troca de saberes através de filmes selecionados a partir do estudo dos Temas Transversais dos Parâmetros Curriculares Nacionais - PCN (BRASIL, 1997), gerando uma aproximação entre bolsistas, professores das escolas e educandos, com o objetivo de propiciar práticas reflexivas em torno de assuntos contemporâneos.

O projeto ocorreu no período compreendido entre os anos de 2015 e 2016 e contemplou duas escolas públicas da cidade de Pelotas, RS. Os referidos educandários, Escola Estadual de Ensino Médio Areal e Escola Estadual de Ensino Fundamental Luis Carlos Correa da Silva, estão situados em áreas urbanas periféricas (respectivamente, bairros Guabiroba e Areal) e atendem crianças e adolescentes de classes sociais diversificadas. A abordagem dos Temas Transversais veio ao encontro do interesse dos alunos das escolas pela inclusão de temáticas do seu cotidiano, as quais necessitavam ser debatidas e refletidas, com vistas a propiciar uma educação plena para todos os envolvidos, alunos das escolas, acadêmicos e professores das escolas e da universidade.

A pesquisa, de cunho qualitativo, apresenta os desdobramentos da trajetória da inserção do cinema nas duas escolas de ensino público, buscando compreender as possibilidades do uso de meios artísticos como o cinema e as artes visuais na educação e partilha do sensível (RANCIÈRE, 2009). Segundo André (1999), a pesquisa qualitativa pressupõe uma visão holística dos fenômenos, englobando todas as interações entre os componentes de uma situação, os aspectos subjetivos do comportamento das pessoas, a relação com o cotidiano e a construção da realidade.

A partir de dados como relatos de alunos e professores das duas escolas, relatórios escritos pelos acadêmicos do Curso de Artes Visuais - Licenciatura (bolsistas do PIBID - Artes Visuais) e registros fotográficos contendo produções artísticas e situações vivenciadas nas atividades desenvolvidas pelo grupo ${ }^{2}$, o material produzido foi posteriormente analisado, ressaltando ideias centrais e/ou núcleos de sentido (MINAYO, 1992) que emergiram com a investigação.

O PIBID é uma iniciativa da Fundação Capes, do Ministério da Educação, que busca o aperfeiçoamento e a valorização da formação de professores para a educação básica. O programa concede bolsas a alunos de licenciatura participantes de projetos de iniciação à docência desenvolvidos por Instituições de Educação Superior (IES) em parceria com escolas de educação básica da rede pública de ensino. Os projetos devem promover a inserção dos estudantes no contexto das escolas públicas desde o início da sua formação acadêmica para que desenvolvam atividades didático-pedagógicas (CAPES, 2016).
Portanto, o Programa de Bolsa de Iniciação à Docência (PIBID) tem sido um acordo do governo federal, que em parceria com escolas e universidades, incentiva uma mudança de cultura da formação de professores no Brasil por promover ações assertivas, visando a valorização e o reconhecimento das licenciaturas para o estabelecimento de um novo patamar para cursos desta formação, realizando um investimento à profissão de magistério. Assim, o PIBID faz parte de "um grande movimento nas políticas públicas com vistas a suprir a defasagem de formação e de valorização do trabalho docente" (SCHEIBE, 2010, p. 996), concedendo bolsas para os estudantes de licenciatura, com vistas ao incentivo pela carreira docente, promovendo a construção da identidade profissional em sua formação inicial.

Desta forma, o projeto de extensão CINE PIBID Transversalizando saberes nas Artes Visuais surgiu de uma proposta inicial da coordenação ${ }^{3}$ do PIBID - Artes Visuais e contou com a participação dos bolsistas do programa, que, voluntariamente e em horários extra das atividades desenvolvidas nas escolas, responsabilizaramse pelo desenvolvimento das ações, realizando registros escritos e fotográficos, como também relatórios de atividades anuais, que permitiram a elaboração do presente texto.

A primeira produção com vistas ao desenvolvimento do CINE PIBID foi a elaboração de um blog para o PIBID - Artes Visuais ${ }^{4}$, que contou com a participação dos bolsistas, com conteúdos fomentados pelos componentes. No blog, tínhamos acesso aos seguintes materiais: notícias, reuniões, experiências, fotos e vídeos, a maioria em permanente construção. Conforme acentuou o acadêmico Lauro:

Criamos esse blog a fim de compartilhar nossas descobertas, reflexões, sentimentos e práticas provindas das trocas entre os bolsistas e as escolas, bem como fomentar as discussões que circundam nossa formação com aqueles que aqui desejarem estabelecer essa troca (BLOG PIBID - ARTES VISUAIS, 2014).

No blog havia uma aba intitulada "Vídeos", onde os bolsistas postavam sugestões de filmes, documentários, videoclips, vídeos e outros materiais audiovisuais que pudessem vir a compor as atividades do CINE PIBID nas escolas, projeto de extensão previsto para início no ano subsequente. Na sessão de vídeos, catalogamos filmes, curtas e documentários com o objetivo de desenvolver o projeto de extensão, focando em temas que possuíssem potencial educativo transversal. Lauro, que trabalhou no projeto, informa que:

Os temas transversais consideram as realidades sociais, relações pessoais, direitos, deveres e compreensão política. São assuntos complementares à educação formal e contribuem para desenvolver as noções de cidadania. Unir o cinema as temáticas abordadas pelos temas transversais: Ética, Pluralidade Cultural, Meio Ambiente, Saúde, Orientação Sexual, Trabalho e Consumo, contribui não só para a compreensão do grupo-foco mas também para familiarizar-se com essa ferramenta educativa e a possibilidade de aplicá-la posteriormente ao ensino nas escolas (PROJETO PARA O CINE PIBID. LAURO. 20.08.2014).

Além do blog, foi criada identidade visual para o projeto de extensão CINE PIBID Transversalizando Saberes nas Artes Visuais, que foi 
desenvolvida por uma bolsista do programa. Por meio do grupo do Facebook "PIBID Artes Visuais UFPEL 2014 "5 foram disponibilizadas as criações e os componentes fizeram uma votação online, em que o número 4 foi escolhido (Fig. 1).

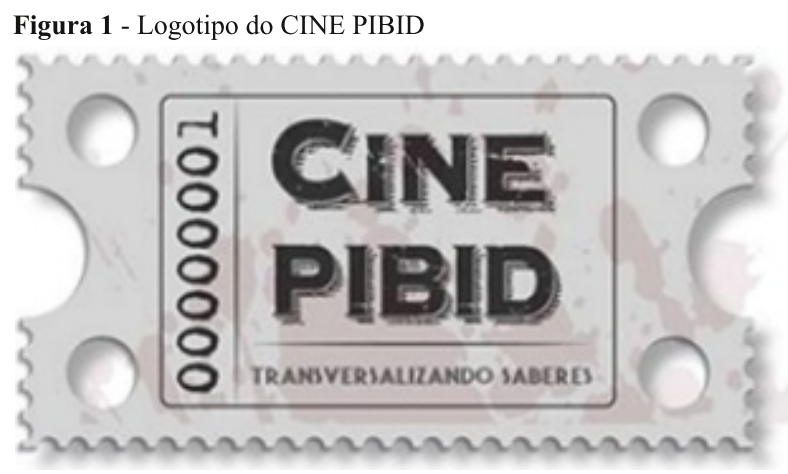

Fonte: Criação da bolsista Shayda C. Peres (2015)

Para o desenvolvimento da proposta, foram adotados os seguintes procedimentos: escolha e estudo de filmes que tratam dos Temas Transversais, realizados pela coordenadora e grupo de bolsistas do PIBID; exploração de espaços para exibição dos filmes: escolas públicas municipais e estaduais e espaços do Centro de Artes; exibição e discussão de filmes. Durante este período inicial, o grupo de bolsistas do PIBID realizaram anotações em cadernos de campo e registros fotográficos, com o objetivo de coletar dados sobre as atividades do evento, propiciando desta forma, novas discussões acerca do trabalho realizado.

Da mesma forma, buscávamos disseminar o uso do cinema como subsídio educativo possível de ser desenvolvido nas escolas, promovendo atividades de formação continuada para os professores das séries finais do ensino fundamental e médio, assim como também oferecer o conhecimento de filmes apropriados para discussões referentes aos Temas Transversais.

\section{A Lei 13.006/2014 - uma possibilidade de inserção do cinema na escola}

A Lei 13.006 de 2014 torna a exibição de filmes e audiovisuais de produção brasileira obrigatória nas escolas de educação básica. A lei assegura que a exibição de filmes de produção nacional constituirá componente curricular complementar integrado à proposta pedagógica da escola, sendo a sua exibição obrigatória por, no mínimo, duas horas mensais. A mesma é um acréscimo ao parágrafo $8^{\circ}$ do artigo 26 da Lei no 9.394, de 20 de dezembro de 1996, que estabelece as diretrizes e bases da educação nacional (BRASIL, 2018).

A exibição prevista de duas horas, de acordo com a lei, promoveria a interação entre alunos, professores e equipe pedagógica da unidade escolar, incentivando práticas artísticas e ampliando o debate sobre as variadas possibilidades de uso do cinema nacional na educação, na busca do fortalecimento de vivências e espaços de diálogos (FRESQUET; MIGLIORIN, 2015).
Ainda que possam existir muitas discussões e estudos sobre tal regulamentação, entendemos que a medida é positiva, buscando disseminar o uso do Cinema como ferramenta educativa nas escolas.

Nas Artes Visuais, o conhecimento da linguagem do cinema - a compreensão sobre o conjunto de planos, ângulos, movimentos de câmera e recursos de montagem que compõem o universo de um filme - é fundamental para o reconhecimento de suas potencialidades expressivas e educativas. Porém, precisamos transcender os limites do uso desta linguagem como ferramenta educativa. Além de promover ao aluno um encontro com o aprendizado de linguagens tecnológicas e o reconhecimento de sua própria cultura e outras culturas possíveis de serem acessadas por diferentes mídias, a formação estética é preponderante na educação das Artes Visuais.

Proporcionar vivências com imagens móveis, como o Cinema, reflete positivamente em experiências escolares nas quais a estética, o lazer, a ideologia e os valores sociais são encontrados numa mesma obra de arte. Assim, o Cinema pode trabalhar conhecimentos históricos, construção de conceitos e ideias visuais a partir de descobertas individuais e coletivas (NAPOLITANO, 2006; ROSENTHAL, 2013).

$\mathrm{O}$ ingresso à cultura digital ocorre naturalmente aos jovens educandos, visto que o acesso à internet por aparelhos eletrônicos, na maioria portáveis, torna o acesso às informações e aos conteúdos disponibilizados na rede facilitado, caracterizando a contemporaneidade como uma civilização centrada na imagem.

O contato com a informação audiovisual ocorre desde a tenra idade. $\mathrm{Na}$ infância, os aparelhos tecnológicos, como televisão, computador, celular e outros artefatos são apresentados às crianças, logo, muitas já possuem domínio dessas ferramentas, utilizando-as com muita frequência.

\section{[...] As crianças e jovens que adentram a escola são formadas, desde muito cedo, no compasso vertiginoso dos artefatos midiáticos. Essa situação de intensa produção, circulação e vivência na cultura midiática traz desafios para os docentes, para o modo de lidar com o conhecimento e se relacionar com os alunos [...] (GUIMARÃES, 2013, p. 221).}

Rodeado de imagens e situações interativas, o contexto vivenciado por muitos jovens fora da escola faz com que ocorra a necessidade da interação destes elementos do cotidiano com os conteúdos escolares. Conforme assegura Andrade (2017, p. 2):

Não ter mais a necessidade da presença física para vivenciarmos um acontecimento em determinado tempo e espaço trouxe uma mobilidade absurda e, muitas vezes, até confusa para alguns. Na busca de algo que possa abarcar essa dinamicidade vivida atualmente, escolhi o cinema como mídia a ser utilizada para desenvolver um diálogo com os educandos, tentando criar um ambiente confortável de discussões, interações e observações de suas ideias e atitudes. Com toda mobilidade que os aparelhos tecnológicos nos trouxeram, é possível levarmos o filme até a escola. As sensações, mensagens e reflexões causadas pelo audiovisual em nossos corpos e mentes não podem ficar restritas ao espaço físico do cinema, merecem chegar às salas de aula de todo país e fomentar a dinâmica do ver, sentir e ouvir um filme. 
A aplicabilidade da Lei 13.006 nas escolas brasileiras abre espaço para que a cultura cinematográfica invada as salas de aula e promova o desenvolvimento do senso estético e crítico, buscando a formação de espectadores do cinema nacional.

No entanto, segundo Deus (2016, p. 6), para que este trabalho seja plenamente desenvolvido na prática educativa necessitamos "partilhar a estética do sensível na escola, ou seja, compreender o cinema como elo integrador dos professores e das áreas de conhecimento. Enfim, significa compartilhar a linguagem cinematográfica entre todos, dentro e fora da escola".

A autora faz referência ao texto de Rancière (2009, p. 15), que sustenta a ideia da partilha do sensível como um

\begin{abstract}
[...] sistema de evidências sensíveis que revela, ao mesmo tempo, a existência de um comum e dos recortes que nele definem lugares e partes respectivas. Uma partilha do sensível fixa, portanto, ao mesmo tempo, um comum partilhado e partes exclusivas. Essas repartições das partes e dos lugares se fundem numa partilha de espaços, tempos e tipos de atividades que determina propriamente a maneira como um comum se presta à participação e como uns e outros tomam parte nessa partilha.
\end{abstract}

Desta forma, por meio da participação em um contexto comum aos integrantes, alunos e professores da escola e acadêmicos e pelo respeito às diferenças, atos estéticos em forma de imagens móveis podem se configurar como experiências possíveis de partilha do sensível.

\section{CINE PIBID nas escolas - relato e reflexão das/nas experiências}

Com o objetivo de partilhar experiências sensíveis (RANCIĖRE, 2009), promovemos a primeira atividade do projeto no mês de outubro de 2015, na Escola Estadual de Ensino Médio Areal, em Pelotas (RS), com o Tema Transversal Meio Ambiente, o qual foi escolhido para ser debatido através de dois curtasmetragens de animação: "A Ilha", de Alê Camargo (2010), e "Man", de Steve Cutts (2012). A atividade teve a duração de 4 horas/aula.

A exibição dos curtas aconteceu na sala de vídeo da escola (Fig. 2) para uma turma de $6^{\circ}$ ano B, onde estavam presentes os bolsistas e professores ligados ao PIBID.

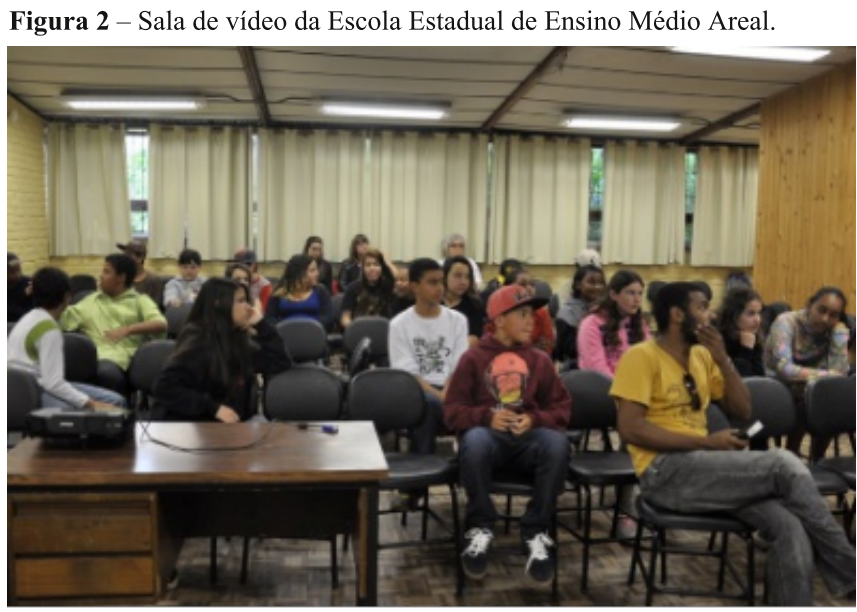

Fonte: Mara Blodorn, 2015
O curta "A Ilha" (CAMARGO, 2010) retrata a dificuldade que os pedestres enfrentam no trânsito das grandes cidades brasileiras. $\mathrm{O}$ cartaz do filme evidencia o olhar do homem perdido em meio ao céu da cidade grande. Impedido de se deslocar em função do tráfego extremo de carros, o personagem torna-se refém deste ambiente. "É necessário sair da ilha para ver a ilha. Não nos vemos se não saímos de nós" - a frase de José Saramago é estampada na entrada do vídeo, sugerindo a premência do olhar endereçado ao outro na vida contemporânea.

"Man" (CUTTS, 2012) aborda como a humanidade age em relação aos outros habitantes do planeta e em relação ao próprio meio ambiente, discutindo o consumo de carne, poluição dos rios, testes em animais e desmatamento florestal, levando o ser humano a um suicídio assumido em função de suas posturas nocivas.

O tema transversal "Meio Ambiente" foi trabalhado por meio destes curtas, com apoio na interdisciplinaridade como uma forma de desenvolver um trabalho de integração dos conteúdos de Artes Visuais com outras áreas de conhecimento, buscando contribuir para sua educação sensível/estética. O PIBID/UFPel visava desenvolver atividades interdisciplinares para conhecer de forma mais aprofundada e integrada a escola, os alunos e professores e também os próprios bolsistas, inseridos naquele contexto. Desta forma, diversas atividades foram sendo desenvolvidas a partir dos vídeos, dentre elas: oficinas de desenho, gravura e colagens, buscando relacionar os temas abordados com o cotidiano dos alunos. No relato abaixo, Amanda, bolsista do PIBID - Artes Visuais, afirma que:

Os grupos passaram a realizar experimentações artísticas, apropriando-se espontaneamente de objetos descartados durante o cotidiano, para a execução de suas respectivas oficinas. Colaboradores do PIBID na oficina de gravura, voluntariamente se reapropriaram de diversos objetos que muitas vezes são descartados, utilizando bandejas de isopor e tampas de garrafas como carimbos/matrizes de impressão (AMANDA. RELATÓRIO, 2015).

Assim, a tentativa de estabelecimento de vínculos com a interdisciplinaridade revelou a reciprocidade presente nas relações que impelem ao diálogo - com os mais próximos, com os mais distantes, com a diversidade, numa

[...] atitude de humildade diante da limitação do próprio saber, atitude de perplexidade ante a possibilidade de desvendar novos saberes, atitude de desafio - desafio perante o novo, desafio em redimensionar o velho - atitude de envolvimento e comprometimento com os projetos e com as pessoas neles envolvidas, atitudes, pois, de compromisso em construir sempre da melhor forma possível, atitude de responsabilidade, mas, sobretudo, de alegria, de revelação, de encontro, enfím, de vida (FAZENDA, 1994, p.82).

Aos poucos, os bolsistas do PIBID perceberam que necessitariam fazer um projeto envolvendo vários saberes - intelectivos, corporais e sensíveis - e, utilizando materiais de fácil acesso, promoveram pausas na exibição dos curtas-metragens. Durante o encontro, estas interrupções serviam como momentos para que os bolsistas levantassem questões, em forma de conversa, referentes ao que estava sendo exibido. 
Após, eram realizadas atividades práticas envolvendo artes visuais e cênicas (Fig. 3).

Figura 3 - Atividades de artes cênicas envolvendo alunos, professores e pibidianos.

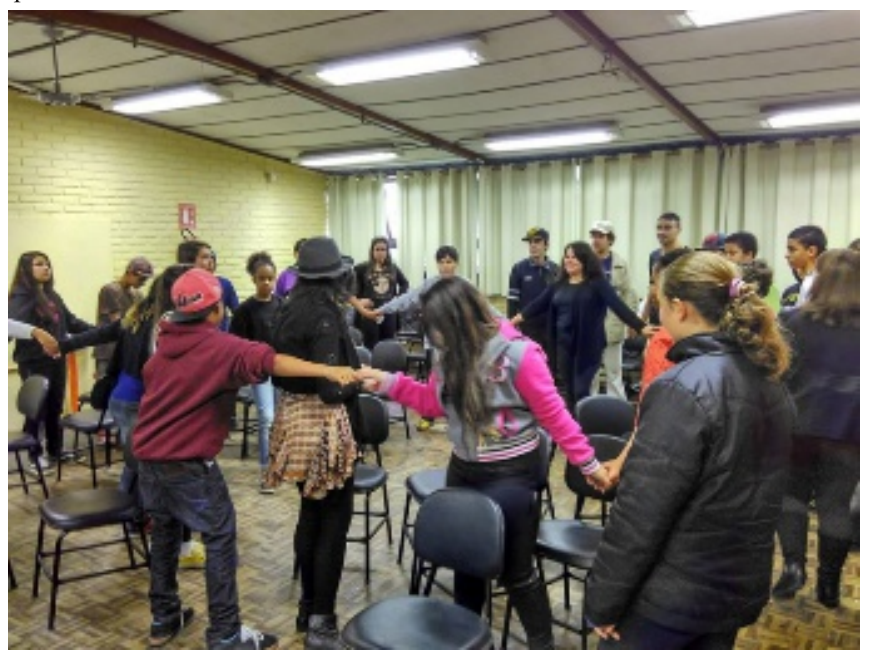

Fonte: Uidis Evangelista, 2015.

As experiências e trocas ocasionadas pelos bolsistas das Artes Visuais, alunos do $6^{\circ}$ ano $\mathrm{B}$ e professores da Escola Estadual de Ensino Médio Areal começam a tomar corpo no segundo semestre de 2015, com uma segunda exibição de filmes. No final de 2015, o grupo do PIBID organizou um retorno à escola com o objetivo de realizar uma oficina a partir do vídeo-documentário "Lixo Extraordinário" (WALKER; JARDIM; HARLEY, 2010). A mesma teve duração de 3 horas/aula. A dinâmica implementada pelo grupo na escola vem ao encontro das artes visuais e suas relações com o cotidiano e as necessidades dos alunos, conforme aponta Uidis, bolsista do PIBID - Artes Visuais:

\begin{abstract}
Esse processo de formação e proposição para a Arte/Educação contextualizada e ligada ao cotidiano, provocadora de reflexão para questões pertinentes ao indivíduo [é fator importante para o nosso trabalho]. [...] [Não queremos com isso criar] ilusões sobre a atuação da Arte na educação, mas que tenhamos consciência de nosso alcance [e] maior segurança ao falar, apresentar e sentir a nossa atuação imediata, existencial e reveladora da realidade que caracteriza o motivo de estarmos aqui, empenhados em propor uma "atividade" alternativa, não-linear, que apresenta [possibilidades para] repensar a escola, fazendo um download para a vida (UIDIS. RELATORIO, 2015).
\end{abstract}

$\mathrm{O}$ vídeo-documentário apresenta o trabalho do artista brasileiro Vik Muniz, realizado com catadores de material reciclável no aterro sanitário do Jardim Gramacho, situado em Duque de Caxias, Rio de Janeiro (MUNIZ, 2010).

Lixo Extraordinário é um vídeo-documentário que apresenta "o estatuto da arte e a questão do lixo na sociedade contemporânea, o árduo trabalho realizado pelos catadores e a possibilidade de transformação que a mudança da percepção artística pode proporcionar" (PORTAL, 2018).

Vik Muniz implementa um ateliê no meio do aterro sanitário e contrata pessoas que trabalhavam com a materialidade presente no lixo para colaborarem com o seu processo criativo, apresentando a elas outras possibilidades no convívio diário com o descarte. Porém, restava o questionamento crítico dos acadêmicos do PIBID: embora o artista tenha colaborado para uma modificação do olhar (dele e dos participantes, provavelmente), poderá, após o trabalho findo, manter na vida daqueles trabalhadores as mudanças provocadas pelo "ateliê" instaurado no período? O que se pode afirmar é que a difícil vida de pessoas que vivem em meio ao lixo e que dependem dele para sua sobrevivência é apresentada e [re]elaborada em forma de arte por Vik Muniz. O artista é considerado um dos maiores expoentes das artes visuais no mundo e trabalha com colagens e montagens de materiais diversos para formar retratos (Fig. 4).

Figura 4 - Fotografia de catadora do Gramacho e recriação de Vik Muniz utilizando materiais recicláveis do aterro.
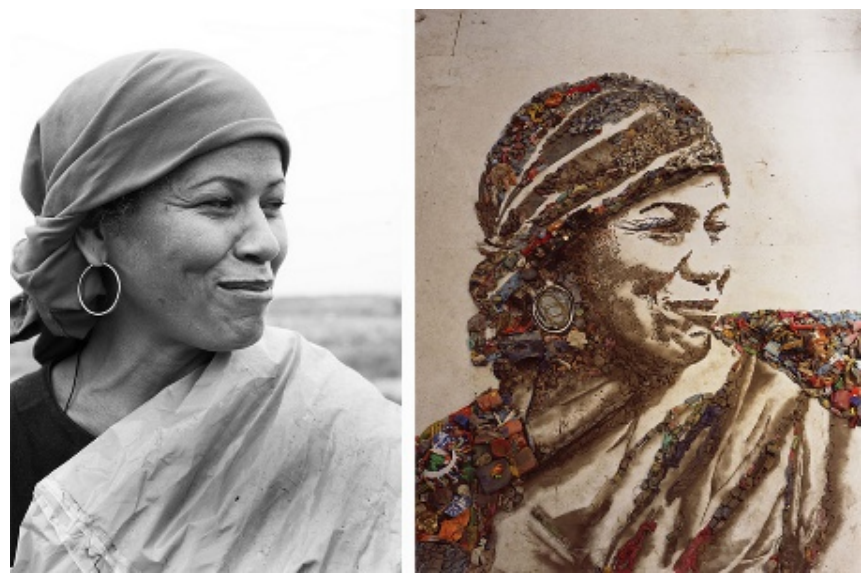

Fonte: MUNIZ, 2010

A exibição do vídeo-documentário propiciou o desencadeamento de diálogo com os alunos, os quais questionaram a validade da proposta do artista, como também reconheceram a importância de tornar a questão do lixo e o descarte urbano visível, mostrando um pouco da vida das pessoas que trabalham como catadores. Buscando o diálogo como forma de exercício da humildade diante da limitação do próprio saber e "atitude de perplexidade ante a possibilidade de desvendar novos saberes", conforme assegura Fazenda (1994, p. 82), os bolsistas do PIBID compreenderam a força do cinema como propositor de diálogo também entre as diferentes disciplinas. Assim, promoveram reflexões
que vão ao encontro ao meio escolar com práticas interdisciplinares e o cotidiano dos alunos Aprendendo através das Artes Visuais novas possibilidades, associando mídias contemporâneas com aprendizagens por meio de músicas e filmes, seu conteúdo ou tema abordado, tudo contribui para um conhecimento cultural do ser pensante, reflexivo e sensível (SÍLVIA, RELATÓRIO, 2015).

O segundo projeto do CINE PIBID foi desenvolvido na Escola Estadual de Ensino Fundamental Luis Carlos Correa da Silva, no segundo semestre de 2015, e foi trabalhado com a turma de $6^{\circ}$ ano 61, em parceria com uma das professorassupervisoras do projeto na escola, Mara Lessa. A atividade teve a duração de 4 horas/aula.

A professora de Língua Portuguesa que atuava na rede estadual há mais de 20 anos entendeu que o CINE PIBID promoveu "uma dinâmica diferente que pôde atrair os alunos e mudar a visão deles em sala de aula, trabalhando o interdisciplinar com o curta "A Ilha", onde foram abordados diversos assuntos éticos e 
de valores sociais" (ENTREVISTA, 2015). Após a exibição do curta, a professora pediu que os alunos escrevessem sobre o filme e os pibidianos colaboraram nas reflexões e questionamentos sobre o vídeo. Conforme assegura o bolsista Ericsson, as vivências com o CINE PIBID promoveram um maior contato com os alunos e o cotidiano escolar:

\begin{abstract}
Como acadêmico de Licenciatura, pesquisador e futuro arte-educador encontro real sentido nesse fazer, pois é uma forma direta de entrar em contato com a realidade escolar e trabalhar nela questões que vivo e dialogo diariamente. Essa pesquisa tem possibilitado através de um trabalho sensível e criativo, inserir a afetividade e a tolerância as diferenças em todos, os espaços que passamos (ERICSSON, RELATÓRIO, 2015).
\end{abstract}

De forma semelhante ao realizado na escola anterior, durante $\mathrm{o}$ encontro eram realizados questionamentos aos alunos em relação ao curta exibido. Foi possível perceber, a partir de conversas em nossas reuniões de área de Artes Visuais, que alguns alunos se mostravam participativos quando solicitados, respondendo às questões levantadas, porém, é importante ressaltar que outros se mostraram desinteressados, ou talvez céticos quanto à importância daquele momento para o aprendizado. Talvez este fato tenha ocorrido pela falta de incentivo à utilização do cinema em sala de aula como estratégia educativa, o que seria bastante relevante para os processos de ensino e aprendizagem, provocando os sentidos e levando arte e cultura às escolas. A partir desta discussão em grupo, pretendeu-se, por meio da arte, proporcionar uma ampliação dos sentidos atribuídos às imagens, trazendo outras formas de abordagens artísticas, em forma de desenhos, pinturas e trabalhos cênicos. Assim, concordamos com as ideias de Canton (2009, p. 45) quando afirma que, por meio da arte, é possível "provoca[r], instiga[r] e estimula[r] nossos sentidos, descondicionando-os, isto é, retirando-os de uma ordem preestabelecida e sugerindo ampliadas possibilidades de viver e de se organizar no mundo".

Assim, foi realizado com os alunos da turma 61 atividades que englobassem o trabalho com a corporeidade associado ao fazer artístico com desenhos e pinturas. Após, os desenhos que formavam as silhuetas dos corpos, em diferentes posições, eram ocupados por palavras, frases e pinturas, onde os alunos procuravam expressar suas sensações e observações em relação ao curta "A Ilha" (Fig. 5).

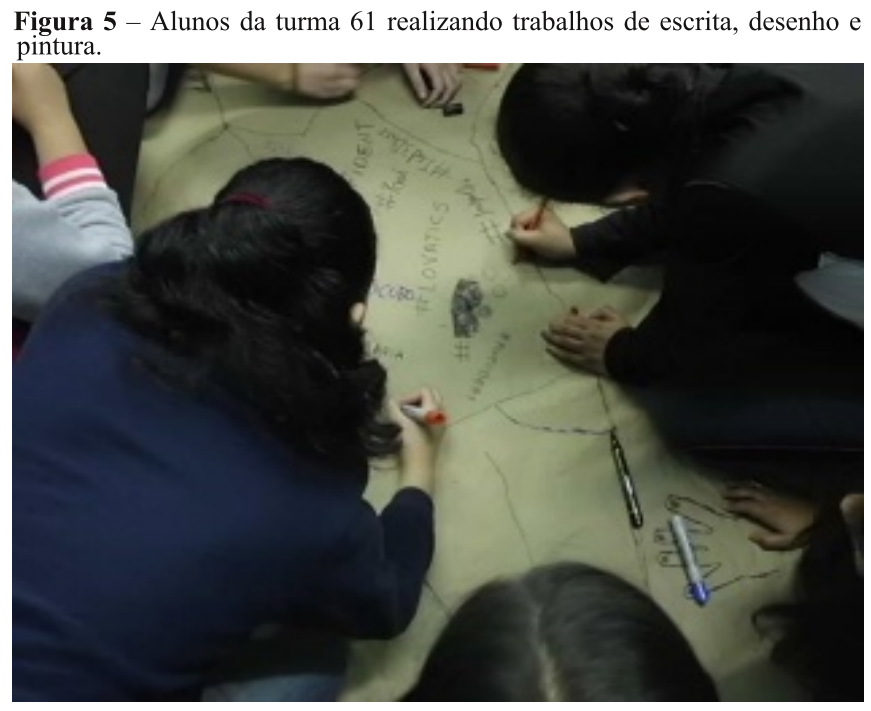

Fonte: Mara Blodorn, 2015.
Segundo a bolsista Mara, uma das idealizadoras deste projeto na escola, o CINE PIBID "começou a plantar sementes e colher resultados positivos em relação ao curta "A Ilha"”. Mesmo que alguns alunos ainda relutassem com a prática, questionando Como? O que vamos aprender?, foi possível compreender que a dinâmica diversificada teve relevância nesta prática, promovendo intencionalmente um descondicionamento corporal. Por meio das discussões e trabalho em grupo, foi possível chegar a diversos temas, como: respeito, diversidade e sexualidade, os quais extrapolaram a temática inicial centrada no "Meio Ambiente", que era presente em "A Ilha" (Fig. 6), segundo a visão dos bolsistas.

Figura 6 - Realização dos alunos da turma 61 "Reconhecendo e respeitando a diversidade".

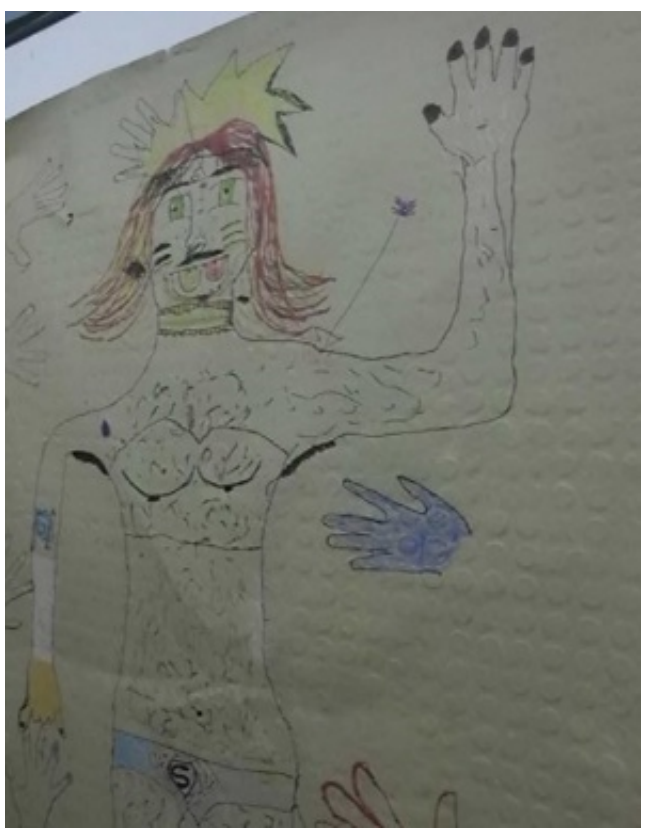

Fonte: Mara Blodorn, 2015.

O processo de envolvimento vivenciado pelos bolsistas do PIBID e os alunos da turma 61 mobilizou sentidos e permitiu novos aprendizados para os futuros professores, ainda em formação. Segundo o entendimento de Mara:

O que mais é interessante é que tanto para os alunos das escolas como para nós, bolsistas, acaba sempre o questionamento sobre o que faremos diferente em outro filme. Nas escolas sempre somos solicitados a continuar o diálogo, mesmo depois da passagem de dias em que a dinâmica e a prática foram aplicadas. Este é para mim o maior dos retornos e de acreditar em um trabalho dinâmico e prazeroso. E claro que alguns pontos não são fáceis de administrar em uma turma de adolescentes, cheios de dúvidas e questionamentos, ávidos por alguém que lhes escute e que os olhem nos olhos e não só na tela de um computador ou tablet ou celular. O subprojeto CINE PIBID têm tudo a ver com a geração de alunos que temos hoje na sala de aula, e é preciso fazer algo que contemple a todos, alunos singulares, com todas as diferenças de um mundo que os bombardeia com informações visuais, com os quais a maioria não sabe nem como lidar. Quando há diálogo, começa a se abrir um mundo com possibilidades de seres pensantes (RELATÓRIO. MARA, 2015). 


\section{O CINE PIBID nas escolas - conclusões e reflexões}

Percebemos, desta forma, que o Projeto CINE PIBID foi um importante instrumento para a melhoria das relações e da autoestima dos professores e dos alunos, promovendo modificações no ambiente escolar em termos de dinâmicas instauradas a partir da ideia da partilha do sensível. Os curtas nacionais foram incorporados à programação, pela necessidade de incentivo às produções da cultura nacional, promovendo uma identificação e valorização dos jovens com o que é produzido no nosso país. Percebemos, pelos dados apresentados, que o projeto foi acolhido de forma positiva pelas escolas estaduais atendidas, gerando boa receptividade do contexto escolar em relação aos acadêmicos do Curso de Artes Visuais - Licenciatura e gerando aprendizagens no que tange às suas inserções na realidade escolar.

Os projetos desenvolvidos foram vistos como possibilidades pedagógicas, em que os participantes puderam expressar seus conhecimentos prévios e outros adquiridos. A experiência contribuiu para o avanço dos bolsistas "como futuros professores, aprofundando as experiências pedagógicas, motivando a organização de atividades e aulas que sejam significativas e criativas para a aprendizagem dos alunos" (RELATÓRIO. DENISE, 2015).

No tocante ao projeto da área de Artes Visuais, os pibidianos destacaram a importância de a docência na escola ser orientada pelo conhecimento da área de estudo, pela afetividade e em ações norteadas pela solidariedade, respeito mútuo, cooperação, tolerância à diversidade, diálogo e companheirismo. "Arte é vida, relação e sensibilidade, sendo assim não poderia ser diferente a relação entre arte/educação e a vivência. Como grupo de arte/educadores em formação estivemos constantemente atravessados pelas experiências de cada um" (RELATÓRIO. UIDIS, 2015).

O CINE PIBID, assim como os demais projetos do PIBID - Artes Visuais, buscou aproximação com a realidade do aluno, reforçando o trânsito com os diversos repertórios na escola - o conhecimento formal e o informal. O ensino da Arte, através do cinema, colaborou na elaboração de novas ideias sobre os fatos do cotidiano, a partir das leituras de imagens propiciadas pelo projeto. Assim, a colaboração do PIBID - Artes Visuais para a parceria EscolaUniversidade se mostra na conjugação dos diferentes contextos educacionais, proporcionando reverberações nos dois campos de atuação para os universitários e seus professores-coordenadores, como também para os professores-supervisores e seus alunos.

\footnotetext{
Notas:

${ }^{1}$ CINE PIBID - Transversalizando saberes nas Artes Visuais, projeto de extensão certificado pelo Siex - Sistema de Informação da Extensão - UFPel, da Pró-Reitoria de Extensão e Cultura da Universidade Federal de Pelotas, com o Código DIPLAN/PREC: 51546055. Descrição do projeto: Formação continuada dos professores dos anos finais do Ensino Fundamental por meio de acões dos bolsistas do PIBID - Artes Visuais, acadêmicos do Curso de Artes Visuais - Licenciatura do Centro de Artes. Discutir, por meio de filmes e/ou vídeos selecionados, em grupos constituídos pelos acadêmicos, professores da rede pública e seus alunos, os Temas Transversais apontados pelos PCN: Etica, Pluralidade Cultural, Meio Ambiente, Saúde, Orientação Sexual, Trabalho e Consumo.
}

2 Os dados produzidos na investigação foram possibilitados ao grupo com a autorização das direçôes das escolas envolvidas, as quais realizam um procedimento padrão de termos individuais de consentimento para seus alunos, assinados pelos respectivos responsáveis, os quais permitem a divulgação de imagens das atividades realizadas na escola e de seus educandos. Desta forma, os termos de consentimento se encontram nas duas escolas participantes do PIBID, que, por meio de parceria federal-estadual, promovem o desenvolvimento do referido programa.

3 Esta autora foi coordenadora do PIBID - Artes Visuais no período de 2014 a 2017, concluindo em março de 2018.

${ }^{4}$ Blog em funcionamento. Disponível em:

http://pibidartesvisuaislicenciatura2014.blogspot.com.br/ Acesso em: 19 ago. 2018.

${ }^{5}$ Página do grupo no Facebook. Disponível em: https://www.facebook.com/groups/pibidufpel14/ Acesso em: 19 ago. 2018.

\section{Referências}

ANDRADE, Viviane Alves de. Cinema brasileiro nas escolas: reflexões e proposta de implementação da lei $13.006 \backslash 14$ na rede municipal do Rio de Janeiro. Revista do Seminário Mídias \& Educação, v. 3, p. 01-11, 2017.

ANDRÉ, Marli Eliza D.A. Etnografia da prática escolar. 3.ed. Campinas: Papirus, 1999.

BRASIL. Secretaria de Educação Fundamental. Parâmetros curriculares nacionais: apresentação dos temas transversais, ética. Secretaria de Educação Fundamental. Brasília: MEC/SEF, 1997.

BRASIL. Presidência da República. Lei N 13.006, 26 de junho de 2014. Disponível em: www.planalto.gov.br/ccivil_03/_ato20112014/2014/lei/113006.htm Ācesso em: 28 jan. 2018.

CANTON, Katia. José Rufino e a Memória. In: CANTON, Katia. Tempo e Memória. Temas da Arte Contemporânea. Editora WMF Martins Fontes, São Paulo, 2009. p. 37-45.

CAMARGO, Alê. A Ilha. 2008. Disponível em: http://portacurtas.org.br/filme/?name=a_ilha8942 Acesso em: 10 out. 2017.

CAPES. Ministério da Educação. PIBID - Programa Institucional de Bolsa de Iniciação à Docência. Disponível em: <http://www.capes.gov.br/educacaobasica/capespibid/pibid > Acesso em: 19 out. 2016.

CUTTS, Steve. Man. 2012. Disponível em: https://www.youtube.com/watch?v=RbpL5xGCXx 8 Acesso em: 05 out. 2017.

DEUS, Ana Iara de. Obrigatoriedade do cinema na escola: uma análise sobre a lei 13.006/14In: ANPED SUL Reunião Científica Regional da ANPED, 11., 2016, Curitiba. Anais... ,Curitiba, PR, 2016. Disponível em: http://www.anpedsul2016.ufpr.br/wpcontent/uploads/2015/11/eixo19_ANA-IARA-SILVA-DEDEUS.pdf Acesso em: 09 out. $2 \overline{0} 16$.

DUARTE, Rosália. Cinema \& educação: refletindo sobre cinema e educação. Belo Horizonte: Autêntica, 2002.

FAZENDA, Ivani. Interdisciplinaridade, teoria e pesquisa. Campinas, SP: Papirus, 1994.

FRESQUET, Adriana; MIGLIORIN, Cesar. Da obrigatoriedade do cinema na escola, notas para uma reflexão sobre a Lei 13.006/14. In: FRESQUET, Adriana. 
(Org.). Cinema e Educação: a Lei 13.006 - Reflexões, perspectivas e propostas. Universo, 2015.

GUIMARÃES, I. V. Os artefatos midiáticos, a pesquisa e o ensino de Geografia. In: ALBUQUERQUE, M. A. M. de; FERREIRA, J. A. de S. (Orgs.). Formação, pesquisa e práticas docentes: reformas curriculares em questão. João Pessoa: Editora Mídia, 2013. p. 219-240.

MINAYO, Maria Cecília de Souza. O Desafio do Conhecimento: pesquisa qualitativa em saúde. São Paulo: Editora Hucitec/Rio de Janeiro: ABRASCO, 1992.

MUNIZ, Vik. Lixo extraordinário. Rio de Janeiro: G. Ermarkoff, 2010.

NAPOLITANO, M. Como usar o cinema na sala de aula. 4. ed. São Paulo: Contexto, 2006.

PORTAL RESÍDUOS SÓLIDOS. Documentário: Lixo Extraordinário. Disponível em: https://portalresiduossolidos.com/documentario-lixoextraordinario/ Acesso em: 07 ago. 2018.

RANCIÈRE, Jacques. A partilha do sensível: estética e política. São Paulo: Editora 34, 2009.

ROSENTHAL, Dália; RIZZI, Maria Christina. Artes. São Paulo: Blucher, 2013. (Série a reflexão e a prática no ensino; v.9 / coordenador Márcio Rogério Cano).

SCHEIBE, Leda. Valorização e formação dos professores para a educação básica: questões desafiadoras para um novo plano nacional de educação. Educação \& Sociedade, v.31, n.112, p. $9811000,2010$.

WALKER, Lucy; JARDIM, João; HARLEY, Karen. Lixo Extraordinário. Reino Unido; Brasil: Almega Projects O2 Filmes, 2010. 1DVD (99 min), color. 